\title{
Progesterone, selected heavy metals and micronutrients in pregnant Nigerian women with a history of recurrent spontaneous abortion
}

\author{
Ajayi OO, *Charles-Davies MA, Arinola OG \\ Department of Chemical Pathology, College of Medicine, University of Ibadan, Ibadan, Nigeria
}

\begin{abstract}
Background: Environmental and endocrine factors have been implicated in the aetiology of recurrent abortion, with poorly understood roles. Luteal phase insufficiency marked with insufficient progesterone secretion has been reported.

Objective: To define the involvement of progesterone, trace metals, and Vitamin E in pregnant women with history of recurrent spontaneous abortion.

Methods: Convenience sampling method was used to recruit 69 pregnant women aged 21-41 years with gestational age of 0-20 weeks in this case-control study. Thirty five (cases) and thirty four (controls) had previous and no history of recurrent spontaneous abortion respectively. Demographic characteristics and $10 \mathrm{mls}$ of blood samples were obtained from each subject. Serum obtained was used for the determination of progesterone, zinc, copper, selenium, iron, magnesium, manganese, chromium, lead, cadmium, and serum vitamin $\mathrm{E}$ by standard methods.

Results: Results showed statistically significant decreases $(p<0.05)$ in the serum zinc, copper, and vitamin $E$ and a significant elevation $(\mathrm{p}<0.05)$ in the serum selenium, lead, and cadmium in cases compared with controls. Insignificant decrease $(\mathrm{p}=0.07)$ was observed in the serum progesterone when cases were compared with controls.

Conclusion: Results suggest that elevated serum heavy metals (cadmium and lead) and reduction of essential micronutrients (zinc, copper and vitamin E) may contribute to recurrent spontaneous abortion.

Keywords: progesterone, oxidative stress, recurrent spontaneous abortion, trace metals, antioxidants

African Health Sciences 2012; 12(2): 153 - 159 http://dx.doi.org/10.4314/ahs.v12i2.12
\end{abstract}

\section{Introduction}

Recurrent abortion is defined as three or more clinically recognized pregnancy losses. i.e. expulsion or extraction of the embryo or foetus weighing less than 500 grammes which is equivalent to approximately 20-22 weeks of gestation ${ }^{1}$. It has remained a significant health problem affecting 2-5 $\%$ of reproducing couples world wide ${ }^{2}$. Although determining the specific cause of recurrent spontaneous abortion can be problematic, reported possible aetiology of recurrent spontaneous abortion include genetic factors, uterine anatomical defects, infection, endocrine, and immunological factors. Increased maternal age and number of prior spontaneous abortions have also been reported as risk factors for foetal loss ${ }^{3,4,5}$.

Luteal phase defect which is abnormal corpus luteum function with insufficient progesterone

*Correspondence author:
Dr Mabel A. Charles-Davies
Department of Chemical Pathology
College of Medicine
University of Ibadan
Ibandan, Nigeria
Tel. +2348023045256
Email: mcharlesdavies@yahoo.com

African Health Sciences Vol 12 No 2 June 2012 production has been reported as the most common aetiologic factor in endocrine abnormalities contributing to spontaneous abortion ${ }^{6,7,8}$. Reports suggest that the incidence of luteal phase defect in reproducing women may be as high as 50\%. Corpus luteum secretion of progesterone is critical for the survival of the pregnancy, until luteal-placental shift occurs at 7 to 9 weeks gestation?

Certain environmental factors equally impact negatively on the human reproductive system. Some of these environmental factors include the heavy metals and poor maternal diet in pregnancy. Studies in animals revealed that the increased uptake of lead, cadmium and other heavy metals interfered with the normal pregnancy course and resulted in abortion, among other physiological dysfunctions ${ }^{1}$. Cadmium can mimic the effect of the endogenous oestrogen receptor agonist, oestradiol (E2), which leads to oestrogen receptor activation. While the effects of cadmium on the endocrine system are no longer in doubt, the exact mode of action is still being studied. Chronic exposure to lead has been reported to increase the risk of spontaneous abortion, particularly at serum level greater than $30>\mathrm{g} / \mathrm{dl}^{1}$. A major mechanism by which these heavy metals act is by the generation of free radicals i.e. 
reactive oxygen species (ROS) and reactive nitrogen species(RNS) that may result in oxidative stress which has been reported to influence the female reproductive system adversely ${ }^{11}$. Reactive oxygen species affect multiple physiological processes from oocyte maturation to fertilization, embryo development and pregnancy. However, the impact of reactive oxygen species is still being studied ${ }^{12}$. Antioxidants which could either be enzymatic or non-enzymatic remain a powerful antidote to free radical generation ${ }^{13,14}$.

Poor maternal diet could also play a role in the aetiology of spontaneous recurrent abortion, particularly in regions of a developing economy (like Nigeria) where many people live below the one dollar a day mark ${ }^{15}$. This makes it difficult for a lot of reproducing women to have access to healthy diets that can sustain the mother and the growing foetus ${ }^{15,16}$. Maternal nutritional deficiencies typically occur as a result of low dietary intakes of essential nutrients ${ }^{17,18}$. Although the negative effects of diets low in energy on pregnancy outcome are well documented, the effects of diets that are low in one or more essential micronutrients have not been adequately studied ${ }^{17}$. However, several observational studies suggest that diets low in essential vitamins and minerals can pose a significant reproductive risk. These essential micronutrients include selenium, zinc, copper, chromium, manganese, magnesium, among others. Selenium is an essential component of the selenoproteins especially glutathione peroxidase required for normal health and reproduction. The requirement of selenium is increased in pregnancy as a result of transport to the growing foetus. In the last few years, some studies suggested that spontaneous abortion in women might be related to selenium deficiency ${ }^{19}$. Zinc is an essential micronutrient that is vital in metabolism. Its deficiency is thought to influence embryonic and foetal development through various mechanisms including; reduced cell proliferation, reduced protein synthesis, increased rate of cellular oxidative damage, increased rate of apoptosis and reduced binding of hormones and transcription factors dependent on zinc-finger proteins ${ }^{20,21}$. Copper is equally important in reproduction. A deficit of copper during pregnancy can result in early embryonic death and gross structural abnormalities including skeletal, pulmonary and cardiovascular defects ${ }^{17}$. Persistent biochemical, neurological and immunological abnormalities also occur. Certain drugs including, D-penicillamine, triethylenetetramine and meso-2, 3 dimercaptosuccinic acids have been reported to cause copper deficiency either directly by chelation or indirectly by altering copper metabolism ${ }^{17,22}$.

This study was aimed at determining the serum levels of progesterone, essential micronutrients and selected heavy metals in pregnant women with history of recurrent abortion which might contribute additional information to the causes of recurrent abortion and aid in its management strategies.

\section{Methods \\ Subjects}

Convenience sampling method was used to recruit 69 pregnant women aged 21-41 years with gestational age of $0-20$ weeks in this case-control study from the Obstetrics and Gynaecology Clinics of the University College Hospital (UCH), Ibadan, Nigeria and Our Lady of Apostle Catholic Hospital (OLA), Oluyoro, Ibadan, Nigeria. Thirty five of them had previous history of recurrent spontaneous abortion (cases). i.e. they had at least three (3) consecutive previous recurrent spontaneous abortion. These were age and sex matched with thirty four apparently healthy pregnant women without history of recurrent spontaneous abortion (controls). The controls were also recruited from $\mathrm{UCH}$ and OLA, Ibadan, Nigeria. Of the 69 study population, 36 subjects ( 20 with history of recurrent spontaneous abortion and16 without history of recurrent spontaneous) were recruited from UCH while 33 subjects (15 with history of recurrent spontaneous abortion and 18 without history of recurrent spontaneous abortion) were recruited from OLA. These mothers were those that reported at the two hospitals during the study period (March 2007August 2008).

Subjects with malignant conditions, those on hormonal medication/preparations and micronutrients were excluded from the study. The ethical approval of the study was obtained from University of Ibadan/UCH(UI/UCH) ethical review committee and the Review Committee of OLA, Oluyoro, Ibadan. University College Hospital $(\mathrm{UCH})$, Ibadan, Nigeria is the first Teaching Hospital in Nigeria and a centre of excellence in medical research and health care delivery in sub-Saharan Africa. It broadly comprises of Clinical and Basic Medical Sciences. Our Lady of Apostle (OLA) Catholic hospital, Oluyoro, Ibadan, Nigeria is a maternity Hospital and also a centre of research with focus on maternal and child health. The Obstetrics and Gynaecology clinics of these hospitals have a 
large population of subjects requiring gynaecological attention. This is the basis of their preference for study.

\section{Collection of Samples}

Ten $\mathrm{ml}$ of venous blood sample was aseptically taken from the antecubital fossa vein using new disposable pyrogen free needles and syringes with minimal stasis. This was put in a plain tube and kept for 1-2 hours on the desk to clot and centrifuged at $500 \mathrm{~g}$ for 10 minutes and the sera separated were stored at $-20^{\circ} \mathrm{C}$ for the determination of the biochemical parameters (progesterone, Vitamin E and trace elements; Zinc, Copper, Iron, Manganese, Magnesium, Chromium, Selenium, Lead, and Cadmium).

\section{Demographic indices}

The demographic characteristics were age, age at menarche, parity, length of menstrual cycle, number of live births, number of previous pregnancies and diet history.

\section{Biochemical Analysis Serum progesterone}

Progesterone in serum was estimated by enzyme linked immunosorbent assay (ELISA) using a commercial kit (Teco Diagnostics Anaheim, CA, USA).

\section{Principle}

This assay is based on the principle of competitive binding between progesterone in the test specimen and progesterone-horseradish peroxidase (progesterone-HRP) conjugate for a constant amount of rabbit anti-progesterone.

\section{Procedure}

All reagents, controls and stored samples to be analysed were brought to room temperature $\left(25^{\circ} \mathrm{C}\right)$ at the beginning of the test. The working solution was prepared by adding $0.1 \mathrm{ml}$. of progesteroneHRP conjugate concentrate $(11 \mathrm{x})$ to $1.0 \mathrm{ml}$. of progesterone-HRP conjugate diluents (i.e. 1:10 dilution). $25 \mu \mathrm{l}$ progesterone standards, controls and patients serum samples were pipetted into appropriate wells of the strip in duplicates. $100 \mu \mathrm{l}$ progesterone-HRP conjugate reagent and $50 \mu \mathrm{l}$ rabbit anti-progesterone reagent were dispensed into each well in succession and were followed by incubation at room temperature for 90 minutes. A solution of 3,3',5,5'-tetramethylbenzidine(TMB) reagent was added and then incubated thus resulting in the development of blue colour. The colour development was stopped by a stop solution and the absorbance measured spectrophotometrically with an ELISA reader at $450 \mathrm{~nm}$. A standard curve was obtained by plotting the concentration of the standard versus the absorbance from which the concentration values of the samples were extrapolated.

\section{Serum trace metals}

Serum zinc, copper, iron, manganese, magnesium, selenium, chromium, lead, and cadmium were determined by atomic absorption spectrophotometry (Buck Scientific, 205, Atomic Absorption Spectrophotometer, Connecticut, USA) based on the direct method described by Kaneko ${ }^{23}$.

\section{Principle}

This method is based on Beer-Lambert's Law. The concentration of a substance is directly proportional to the amount of radiant energy absorbed and inversely proportional to the logarithm of the transmitted radiant energy ${ }^{24}$.

\section{Procedure}

The frozen serum samples were brought to room temperature. This was followed by preparation of the samples for analysis as indicated below: Selenium, chromium, magnesium, lead, cadmium; $1 \mathrm{ml}$. of serum was deproteinized with $9 \mathrm{ml}$ of $10 \%(\mathrm{w} / \mathrm{v})$ trichloroacetic acid (TCA) in 0.1 lanthanum solution, the resulting supernatant was diluted with $0.11 \%$ lanthanum before aspirating into the Atomic Absorption Spectrophotometer (AAS).

Iron: The serum was diluted with $20 \% \mathrm{TCA}$ in the ratio of 1:2 and was subsequently heated at 900C for 15 minutes. It was centrifuged and the resulting supernatant aspirated into the AAS.

Manganese and Copper: The serum was diluted in the ratio of 1:1 with ultrapure water and then aspirated into the AAS.

Zinc: The serum was diluted with ultrapure water in the ratio of 1:4 and then aspirated into the AAS. Working standard solutions were prepared by diluting the stock standard with ultrapure water and the concentration $(\mu \mathrm{g} / \mathrm{dl}): 4.010,4.003,4.003,4.001$, $3.997,3.998,4.001,4.002,4.000$ were used for the standardization of $\mathrm{Zn}, \mathrm{Cu}, \mathrm{Pb}, \mathrm{Se}, \mathrm{Cd}, \mathrm{Mg}, \mathrm{Mn}, \mathrm{Cr}$ and Fe respectively. 


\section{Serum Vitamin E}

Serum tocopherol (vitamin E) was estimated by high performance liquid chromatography HPLC)(Waters,USA).

\section{Principle}

This is a separation process whereby a mixture of solutes dissolved by another differential distribution of the solutes between two phases ${ }^{24}$.

\section{Procedure}

Serum sample was pretreated with ethanol to separate saponifiable components which could interfere with Vit. E determinations after which tocopherol was separated on Waters symmetry C18 column $(3.9 \mathrm{~mm} \times 150 \mathrm{~mm}$ with waters symmetry C18 $(3.9 \mathrm{~mm} \times 10 \mathrm{~mm})$ guard column between an initial mobile phase of acetonitrile in water and then acetonitrile. The flow rate was $1 \mathrm{ml} / \mathrm{min}$.

\section{Sample Size}

The sample size was calculated based on the formula of Hunt et al. ${ }^{2}$ with $4.5 \%$ prevalence of recurrent spontaneous abortion and 95\% confidence level.

\section{Statistical analysis}

The data were carefully entered, checked, cleaned and properly coded into Microsoft excel software package on a personal computer (PC). The data were subsequently transferred to Statistical Package for Social Scientists (SPSS) version 16 for the statistical analysis. The continuous variables analyzed include serum progesterone, zinc, copper, vitamin E, lead, cadmium, manganese, magnesium, iron, chromium and selenium. Student's ( $\mathrm{t}$-test was used for the comparison of $\mathrm{x} \pm$ S.D at $95 \%$ confidence level. A $\mathrm{p}<0.05$ was considered significant

\section{Results}

Table 1 shows that the mean ages of cases and controls were $30.50+0.88$ years and $30.09+0.80$ years respectively. There were significant differences $(\mathrm{p}<0.05)$ in the mean values of Number of Previous Pregnancies (NPP), and number of Live Birth (NLB) while differences in age, length of menstrual cycle, and age at menarche were not statistically significant $(\mathrm{p}>0.05)$.

Table 1: Demographic indices of pregnant women with history of recurrent spontaneous abortion compared with controls

\begin{tabular}{lllr}
\hline & Controls $(\mathbf{n}=\mathbf{3 4})$ & Cases $(\mathbf{n}=\mathbf{3 5})$ & p-values \\
\hline Age (years) & $30.09 \pm 0.80$ & $30.50 \pm 0.88$ & 0.549 \\
LMC (days) & $27.26 \pm 0.17$ & $27.34 \pm 0.20$ & 0.760 \\
AM (years) & $13.33 \pm 0.24$ & $13.66 \pm 0.26$ & 0.540 \\
NPP & $2.56 \pm 0.12$ & $4.09 \pm 0.26$ & $0.001^{*}$ \\
NLB & $2.44 \pm 1.41$ & $0.31 \pm 0.11$ & $0.002^{*}$ \\
\hline
\end{tabular}

values are in mean $\pm \mathrm{SD} \quad *=\mathrm{p}<0.05$ is significant $\mathrm{n}=$ number of subjects $\mathrm{AM}=$ age at menarche $\mathrm{NLB}=$ number of live births $\mathrm{LMC}=$ length of menstrual cycle $\mathrm{NPP}=$ number of previous pregnancies

Table 2 shows the mean \pm s.d. of zinc, iron, copper, magnesium, manganese, Selenium, chromium, vitamin E, progesterone, lead and cadmium in cases and controls. There were significant differences $(p<0.05)$ in mean concentrations of Zinc, Copper,
Selenium and vitamin E, lead and cadmium while mean levels of iron, magnesium, manganese and chromium were not statistically significant $(\mathrm{p}>0.05)$. There was a non-significant decrease $(p=0.07)$ in progesterone level in cases compared to the controls. 
Table 2: Mean levels of micronutrients, heavy metals and progesterone of pregnant women with history of recurrent spontaneous abortion compared with pregnant women without history of recurrent spontaneous abortion

\begin{tabular}{llll}
\hline & Controls $(\mathbf{n}=34)$ & Cases $(\mathbf{n}=35)$ & p-values \\
\hline Zinc $(\mu \mathrm{g} / \mathrm{dl})$ & $99.25 \pm 2.14$ & $69.26 \pm 0.69$ & $0.001^{*}$ \\
Iron $(\mu \mathrm{g} / \mathrm{dl})$ & $102.26 \pm 3.53$ & $104.46 \pm 3.49$ & 0.660 \\
Copper $(\mu \mathrm{g} / \mathrm{dl})$ & $122.45 \pm 2.71$ & $94.25 \pm 3.07$ & $0.001^{*}$ \\
Magnesium $(\mu \mathrm{g} / \mathrm{dl})$ & $225.16 \pm 6.67$ & $227.63 \pm 7.21$ & 0.800 \\
Manganese $(\mu \mathrm{g} / \mathrm{dl})$ & $70.35 \pm 1.92$ & $85.37 \pm 15.68$ & 0.340 \\
Selenium $(\mu \mathrm{g} / \mathrm{dl})$ & $78.52 \pm 1.76$ & $96.10 \pm 1.53$ & $0.001^{*}$ \\
Chromium $(\mu \mathrm{g} / \mathrm{dl})$ & $44.45 \pm 1.16$ & $45.16 \pm 1.26$ & 0.680 \\
Vitamin E $(\mathrm{mg} / \mathrm{l})$ & $9.13 \pm 0.27$ & $4.63 \pm 0.15$ & $0.002^{*}$ \\
Lead $(\mu \mathrm{g} / \mathrm{dl})$ & $60.70 \pm 1.40$ & $85.96 \pm 1.09$ & $0.001^{*}$ \\
Cadmium $(\mu \mathrm{g} / \mathrm{dl})$ & $2.49 \pm 0.09$ & $4.58 \pm 0.77$ & $0.001^{*}$ \\
Progesterone $(\mathrm{ng} / \mathrm{ml})$ & $45.32 \pm 3.03$ & $38.37 \pm 2.26$ & 0.070 \\
\hline
\end{tabular}

values are in mean \pm SD $\quad *=\mathrm{p}<0.05$ is significant $\mathrm{n}=$ number of Subjects $\mu \mathrm{g} / \mathrm{dl}=$ microgram per deciliter $\mathrm{mg} / \mathrm{l}=$ milligram per litre $\mathrm{ng} / \mathrm{ml}=$ manogram per mililitre

\section{Discussion}

This present study was designed to determine the serum levels of progesterone, essential micronutrients, and heavy metals in pregnant women with history of recurrent abortion which might contribute additional information to the causes of recurrent abortion and aid in its management strategies.

Pregnancy involves a complex interaction between genetic, anatomic, endocrine, immune, and neurological systems. When any of these is disturbed, the pregnancy may be lost.

Studies have shown that about $17 \%$ of women with recurrent abortion may have a potential endocrine abnormality, with the majority having insufficient progesterone production ${ }^{7}$. Progesterone is vital in the maintenance of pregnancy and there are reports that insufficient production of progesterone could result in poor pregnancy outcome $^{25}$. In this study, there was an insignificant decrease in progesterone level in cases compared with controls. This slight decrease in progesterone level might have contributed to pregnancy loses in the cases.

The role of the environment (exposure to toxicants, maternal nutrition and lifestyle) in the aetiology of spontaneous abortion remains poorly understood. The role of certain trace metals particularly zinc and copper in steroidogenesis has been well established ${ }^{26}$, but the roles of manganese, magnesium, chromium and even iron in steroidogenesis have not been clearly defined. It is likely that chromium, magnesium, manganese and iron may be relevant in steroidogenesis particularly progesterone synthesis but may not be important as causative factors in recurrent abortion.

Micronutrient deficiency in women of reproductive age is recognized as a major public health problem in many developing countries ${ }^{27,28}$. Pregnant women are particularly vulnerable to nutritional deficiencies because of the increased metabolic demands imposed by the growing conceptus $^{29}$. Several observational and interventional studies suggest that diets low in essential micronutrients can pose a significant reproductive risk $^{17}$. Oxidative stress is generated during normal placental development. Some micronutrients function as essential co-factors or antioxidants. Insufficient supply of antioxidants could exaggerate oxidative stress within both the placenta and maternal circulation with adverse pregnancy outcomes ${ }^{29}$. The importance of adequate micronutrient intake during the periconceptional and pregnancy periods have been reported ${ }^{30}$. In this present study, there were significant decreases $(p<0.05)$ in the serum levels of zinc, copper and Vitamin $\mathrm{E}$ of pregnant women with history of recurrent spontaneous abortion compared with the controls. These findings were partly similar to the findings of Kiiholma et al. ${ }^{31}$ who also observed significant low plasma levels of zinc and copper in non pregnant women with recent experience of recurrent abortion. Copper and zinc 
are essential co-factors for superoxide dismutases with reduced activity in pathological pregnancy ${ }^{29}$.

Low serum zinc levels have been suggested to influence embryonic and foetal development through various mechanisms such as reduced cell proliferation, reduced protein synthesis, and increased rate of cellular oxidative damage $e^{20,21}$. Copper is recognized as an essential trace element required for normal metabolic processes. Studies have shown that deficiency of copper causes lipid peroxidation resulting in high oxidative damage which can adversely affect the foetus including embryonic death, structural abnormalities, cardiovascular, immunological and neurological defects ${ }^{17}$.

Vitamin $\mathrm{E}$ is one of the most potent non enzymatic antioxidants. Various studies have shown that adequate intake of vitamin $\mathrm{E}$ in pregnant women enhances term delivery and has been shown to protect and sustain the endometrial membrane from free radicals. Its deficiency has been associated with foetal death ${ }^{17}$. Reduced zinc, copper and vitamin $\mathrm{E}$ in women with history of recurrent spontaneous abortion might have been caused by oxidative stress in these subjects.

The trace mineral selenium is an essential component of the selenoproteins, especially glutathione peroxidase, required for normal health and reproduction. In this present study, there was significant increase in serum selenium level in pregnant women with history of recurrent spontaneous abortion, as compared with pregnant women without history of recurrent spontaneous abortion. This is contrary to findings by others ${ }^{32}$. It however, requires further study. Cadmium and lead enhance the production of reactive oxygen species. Their elevation in pregnant women with history of recurrent spontaneous abortion compared with the control group suggests an increased production of reactive oxygen species. The role of cadmium in recurrent spontaneous abortion is still being studied although it is toxic at low levels for a long term exposure ${ }^{33}$. The finding of higher lead concentration in pregnant women with history of recurrent spontaneous abortion compared with pregnant women without history of recurrent spontaneous abortion is consistent with the findings of HertzPicciotto $^{10}$.

\section{Conclusion}

Elevated serum heavy metals (cadmium and lead) and reduction of essential trace metals (zinc, copper and vitamin E) may contribute to recurrent spontaneous abortion. It is suggested that multinutrient supplements be given to pregnant women with history of recurrent spontaneous abortion so as to reduce the risk of pregnancy loss.

\section{References}

1. Coulam CB, Stephen M, Stern JJ, Clark DA. Immunotherapy for recurrent pregnancy loss: Analysis of results from clinical trials. Am. J. Reprod. Immunol 1996; 35: 352-359.

2. Hunt JS. Immunologically relevant cells in the uterus. Biol. Reprod 1994; 50:461-470.

3. Bulletti C, Flamigni C, Giacomucci E. Reproductive failure due to spontaneous abortion and recurrent miscarriage. Hum Reprod Update 1996; 2:118-136.

4. Grudzinskas JG. Miscarriage. Ectopic pregnancy and trophoblastic disease in Edmonds .K.(ed.). Dewhursts Textbook of Obstetrics and Gynaecology for postgraduates. 6th edition. Oxford: Blackwell Science Ltd, 1999.

5. Kroon B, Harrison K, Martin N, Wong B, Yazdani A. Miscarriage karyotype and its relationship with maternal body mass index, age and mode of conception. Fertil. Steril. 2011; 95: 1827-1829.

6. Norman R.J, Mcloughlin JW, Borthwick GM, Yohkaichiya T, Matthews CD, Maclennan AH et al. Inhibin and relationship to gonadotropin and steroid profiles. Fertil Steril 1993; 59: 130137.

7. Randine L.(2003). Luteal phase defect. Medical articles NR1-08 http://www.acudenver.com/ docs/articles rl8.pdf).

8. Fatemi HM, Popovic-Todonovic, Papanikolaou E, Donoso P, Davroey P. An update of luteal phase support in stimulated IVF cycles. Hum. Rep Update 2007; 13:581-590.

9. Essah PA, Cheang KI, Nestler JE. The pathophysiology of miscarriage in women with polycystic ovary syndrome. Review and proposed hypothesis of mechanisms involved. Hormones 2004; 3:221-227.

10. Hertz-Picciotto I. The evidence that lead increases the risk for spontaneous abortion. $A m$ J Ind Med 2000; 38:300-309.

11. Agarwal A, Allamaneni SS. Role of free radicals in female reproductive diseases and assisted reproduction. Reprod Biomed Online 2004; 9:338347.

12. Ishikawa M. Oxygen radicals-superoxide dismutase system and reproduction medicine. 
Nippon Sanka Fujinka Gakkai Zasshi 1993; 45:842-848.

13. Yu BP. Cellular defenses against damage from reactive oxygen species. Physiological Reviews 1994; 74:139-162.

14. Agarwal A, Gupta S, Sekhon L, Shah R. Redox considerations in female reproduction function and associated reproduction: From molecular mechanism to health implications. Antioxid Redox Signal 2008, 10:1375-403.

15. Okonofua FE. Female and male infertility in Nigeria. Studies on the epidemiology of infertility in Nigeria with special reference to the role of genital tract infection and sexual reproductive risk factors (A Thesis). Karolinska Institutet Stockholm, Sweden, 2005.

16. Mohammed Y, Yakoob Y, Pervez K, Zulfiqar AB. Maternal Mineral and Vitamin Supplementation in Pregnancy. Expert Review of Obstetrics and Gynaecology 2010; 5: 241-256.

17. Keen C L, Uriu-Hare JY, Hawk SN, Jankowski MA, Daston GP, Kwik-Uribe C L, et al. Effect of copper deficiency on prenatal development and pregnancy outcome. Am. J. Clin. Nutr 1998; 67: 1003S-1011S.

18. King JC. Specific nutrient requirements: trace elements. In: Gershwin ME, German JB, Keen CL, eds. Nutrition and Immunology; Principles and Practice. Totowa N J: Humana Press, Inc., 2000.

19. Barrington JW, Lindsay P, James D, Smith S, Roberts A. Selenium deficiency and miscarriage: a possible link? Br J Obstet Gynaecol 1996; 103:130-132.

20. Jankowski-Hennig MA, Clegg MS, Daston GP, Rogers JM, Keen CL. Zinc-deficient rat embryos have increased caspase 3-like activity and apoptosis. Biochem. Biophys. Res. Commun 2000; 271: 250-256.

21. Mackenzie GG, Zago MP, Keen CL, Oteiza PI. Low intracellular zinc impairs the translocation of activated NF-kappa B to the nuclei in human neuroblastoma IMR-32 cells. J. Biol. Chem 2002; 277: 34610-34617.
22. Taubeneck MW, Domingo JL, Llobet J M, Keen CL. Meso-2,3-dimercaptosuccinic acid (DMSA) affects maternal and foetal copper metabolism in Swiss mice. Toxicology 1992; 72: 27-40.

23. Kaneko JJ. Clinical biochemistry of animals. 4th ed. New York: Academic Press inc.1999.

24. Kaplan LA, Pesce AJ, Kazmierczak SC, editors. Clinical Chemistry: Theory, Analysis, Correlation. 4th edition. St. Louis: Mosby; 2003.

25. Arndt WJ, Hoile AJ, Bauer ML, Kirsch JD, Schimek DE, Odde KG, Vannahme KA Effect of post-insemination progesterone supplementation on pregnancy rate in dairy cow. Can.J Vet Res 2009; 73: 271-274.

26. Allen LH. Multiple Micronutrients in pregnancy and lactation: An overview. Am. J. Clin. Nutr 2005; 81:1206S.

27. Ramakrishman U. Prevalence of micronutrient malnutrition world wide. Nutr. Rev 2002; 60: S46-S52.

28. Christian TJ. Inherited thrombophilia: impact on human reproduction. American Journal of Reproductive Immunology 2003; 50: 20-32.

29. Mistry HD, Paula J, Williams PJ. The Importance of Antioxidant Micronutrients in Pregnancy. Oxid Med Cell Longev, 2011; 2011: 841749

30. Cetin I, Berti C, Calabrese S (2010). Role of micronutrients in the periconceptional period. Human Reproduction Update 2010; 16: 80-95.

31. Killholma P, Gronroos M, Erkkola R, Pakarinen P, Nanto V. The role of calcium, copper, iron and zinc in preterm delivery and premature rupture of fetal membranes. Gynecol Obstet Invest 1984;17:194-201.

32. Zachara BA, Dobrzynski W, Trafikowska U, Szymanski W. Blood selenium and glutathione peroxidases in miscarriage. BJOG 2001; 108: 244-247.

33. Young T, Downey G, Maheshwari MB, Nicholl DJ (2010). A cupric pregnancy: thirteenth time lucky. Short report. Journal of the royal society of medicine (JRSM), 2010; 104: 45 (http:// shortreports.rsmjournals.com/content/1/6/ 51/.full) 